\title{
Características do transplante cardíaco neonatal e infantil
}

\author{
Miguel BARBERO-MARCIAL*, Estela AZEKA*, Paulo Roberto CAMARGO*, Marcelo B. JATENE*, \\ Arlindo RISO*, José Otávio C. AULER JÚNIOR* ${ }^{\star}$ José SOARES*, Cristina MONTEIRO*, \\ Davi UIP*, Luis CAMARGO*, Sílvia SANTOS*, Verônica COELHO*, Edmar ATIK*, \\ Munir EBAID*, Adib D. JATENE*
}

RBCCV 44205-291

Barbero-Marcial M, Azeka E, Camargo P R, Jatene M B, Riso A, Auler Júnior J'O C, Soares J, Monteiro C, Uip D, Camargo L, Santos S, Coelho V, Atik E, Ebaid M, Jatene A D - Caracteristicas do transplante cardiaco neonatal e infantil. Rev Bras Cir Cardiovasc 1996; 11 (2): 60-6.

RESUMO: Objetivo: Relatar as características do transplante cardiaco neonatal e pediátrico em crianças portadoras de cardiopatias complexas e cardiomiopatias refratárias à terapêutica convencional. O presente trabalho mostra a experiência de três anos e meio deste procedimento no Instituto do Coração HC-FMUSP.

Métodos: A metodologia empregada consistiu-se na técnica cirúrgica nos casos de cardiopatias congênitas, critérios de indicação para o transplante e viabilidade do doador, manuseio pós-operatório, imunosupressão, prevenção e tratamento de potenciais complicaçōes.

Resultados: De novembro de 1992 a junho de 1996, 14 crianças foram transplantadas com idade de 12 dias a seis anos (média de 2,2 anos); $57 \%$ do sexo masculino; peso de $3,5 \mathrm{~kg}$ a $17,8 \mathrm{~kg}$ (média de 10,3 kg). Os doadores tinham de 21 dias a dez anos de idade(média de 4,4 anos); $80 \%$ do sexo masculino; peso variando de 3,8 a $20 \mathrm{~kg}$ (média de $14,3 \mathrm{~kg}$ ). A sobrevida foi de $85,7 \%$ (2 óbitos em 14 pacientes). O tempo de seguimento foi de um mês a três anos e seis meses (média de 16 meses). As principais complicações foram hipertensão arterial sistêmica, rejeição aguda e infecção. O número de rejeiçōes por paciente foi de 3,5 episódios e de infecção foi de 3,3 episódios.

Conclusão: O transplante cardíaco consistiu-se em promissora opção terapêutica com sobrevida de $85,7 \%$ a médio prazo.

DESCRITORES: Transplante cardiaco, neonatal. Transplante cardiaco, pediátrico.

\section{INTRODUÇÃO}

O transplante cardíaco neonatal e pediátrico tem proporcionado sobrevida e melhora da qualidade de vida em grupo de crianças portadoras de cardiopatias complexas e cardiomiopatias refratárias. No entanto, é importante salientar que o transplante cardíaco nesta faixa etária apresenta características próprias, que devem ser valorizadas para minimizar eventuais complicações.
O primeiro transplante cardíaco entre humanos foi realizado por BARNARD (1), em 1967. Já o primeiro relato de transplante neonatal é do mesmo ano, quando KANTROWITZ et al. (2) tentaram, sem sucesso, o transplante em recém-nato portador de anomalia de Ebstein. Somente com a introdução da ciclosporina como droga imunosupressora de base, houve novo alento, motivando vários grupos a reiniciarem seus programas até então suspensos pela dificuldade no manuseio da rejeição (3).

\footnotetext{
Trabalho realizado no Instituto do Coração do Hospital das Clínicas da Faculdade de Medicina da Universidade de São Paulo. São Paulo, SP, Brasil. Entregue para publicação em junho de 1996.

* Do Instituto do Coração do Hospital das Clínicas da Faculdade de Medicina da Universidade de São Paulo.

Endereço para correspondência: Miguel Barbero-Marcial. Av. Enéas de Carvalho Aguiar, 44. Divisão Cirúrgica. CEP: 05403-000. Cerqueira Cesar - São Paulo, SP, Brasil. Tel: (011) 3068-5089.
} 
Barbero-Marcial M, Azeka E, Camargo PR, Jatene M B, Riso A, Auler Júnior J O C, Soares J, Monteiro C, Uip D, Camargo L, Santos S, Coelho V, Atik E, Ebaid M, Jatene A D - Caracteristicas do transplante cardíaco neonatal e infantil. Rev Bras Cir Cardiovasc $1996 ; 11(2): 60-6$,

A aplicação clínica do transplante, principalmente no período neonatal, deve-se ao pioneirismo de BAYLEY et al. (4), que, em 1984, realizaram o primeiro xenotransplante em criança portadora de síndrome de hipoplasia de coração esquerdo (SHCE) e, um ano após ${ }^{(5)}$ realizaram o primeiro transplante em recém-nato com a mesma cardiopatia, sendo que a criança encontra-se bem até os dias atuais (6).

Este trabalho tem como objetivo relatar as características do transplante cardíaco neonatal, pediátrico e a experiência a médio prazo, iniciada em 1992 com transplante em 1 recém-nato portador de síndrome de hipoplasia de coração esquerdo, no Instituto do Coração do HC-FMUSP (7)

\section{CASUÍSTICA E MÉTODOS}

No Instituto do Coração do HC-FMUSP, no período de novembro de 1992 a junho de 1996, 14 crianças com idade variável entre 12 dias de vida a 6 anos (média de 2,2 anos) foram submetidas a transplante de coração ortotópico. Oito crianças eram do sexo masculino. O peso variou de $3,5 \mathrm{~kg}$ a $18 \mathrm{~kg}$ (média de 10,3 kg).

A indicação para transplante foi motivada por cardiopatia congênita em 4 casos: síndrome de hipoplasia de coração esquerdo (2), atresia pulmonar com septo íntegro e circulação coronária dependente do ventrículo direito (1), comunicação interventricular e fibroelastose (1); por cardiomiopatia dilatada em 8 e por cardiomiopatia restritiva no restante.

Os 2 neonatos portadores de sindrome de hipoplasia de coração esquerd̆o encontravam-se clinicamente em bom estado geral, hemodinamicamente estáveis, em uso de prostaglandina E1. O neonato portador de atresia pulmonar canal dependente com sinusóides que comunicavam amplamente - ventrículo direito à circulação coronariana foi submetido a cirurgia paliativa de Blalock-Taussig com 14 dias de vida. Após isto, ficou liberado para transplante, mantendo-se em bom estado geral, com cianose discreta. A criança portadora de comunicação interventricular foi submetida a correção cirúrgica com 4 meses e evoluiu com insuficiência cardíaca refratária após 2 anos.

As crianças portadoras de cardiomiopatia apresentavam-se em insuficiência cardiaca refratária, em uso de medicação anti-congestiva. O ecodopplercardiograma revelou uma fração de encurtamento entre $10 \%$ a $14 \%$ (média de $12 \%$ ). No estudo hemodinâmico, em condição basal o indice de resistência vascular pulmonar variou entre 1,2 a 4,9 unidades Woods (média de 2,2 unidades Woods).

Os doadores apresentaram idade variável de
21 dias a 10 anos (média de 4,4 anos), com peso de $3,8 \mathrm{~kg}$ a $30 \mathrm{~kg}$ (média de $14,3 \mathrm{~kg}$ ). As causas de morte encefálica foram: traumatismo crânio-encefálico, 7 pacientes; tumores cerebrais, 2; mal convulsivo, 2; afogamento, 1; anóxia neonatal, 2 pacientes.

Os critérios de inclusão do receptor foram: crianças menores de 6 anos, estabilidade hemodinâmica, ausência de quadros septicêmicos, de alterações neurológicas, renais, anormalidades cromossômicas e de distúrbios psiquiátricos entre os responsáveis da criança.

$\mathrm{Na}$ avaliação do receptor, foram necessários o conhecimento dos seguintes parâmetros: tipagem sangüinea e dos antígenos de histocompatibilidade (HLA); painel imunológico (PRA), hematológico (hemograma, coagulograma), sorologia (HIV, hepatite B, C, sífilis, Chagas, toxoplasmose, citomegalovírus, Ebstein-Barr); tomografia de crânio, eletrocardiograma, ecodopplercardiograma, estudo hemodinâmico, ventriculografia radioisotópica e cintilografia com gálio 67 .

Quanto ao redor, uma vez apresentando tipagem sangüinea e peso compativeis com o receptor (tipagem sangüinea concordante com o sistema $A B O$ e peso do doador até $250 \%$ superior ao do receptor), continuou-se a investigação para confirmação de morte encefálica através de angiografia cerebral ou eletroencefalograma. Do ponto de vista cardiovascular, os doadores apresentaram radiografia de tórax normal, ecodopplercardiograma com fração de encurtamento maior que $25 \%$ e ausência de defeitos congênitos. Avaliou-se o doador do ponto de vista infeccioso através de hemograma, sorologia para HIV, sifilis, hepatite B, C, Chagas, citomegalovírus e toxoplasmose. Realizou-se o cross-match em todos os casos ( prova entre células do doador e plasma do receptor cuja positividade excluiu a possibilidade de utilização do órgão). A relação de peso do doador foi, em média, superior $140 \%$ ao do receptor. O painel imunológico do receptor variou de zero até $7 \%$. Todos apresentaram prova de cross-match negativa. Quanto a sorologia HIV, hepatite B, C, Chagas, sífilis, foram todas negativas, tanto nos receptores quanto nos doadores.

No manuseio per-operatório, confirmando-se a viabilidade do doador, deixou-se o receptor em jejum, iniciou-se a ciclosporina enquanto se aguardava o resultado da sorologia do doador e o do crossmatch. Imediatamente antes do transplante, administrou-se solumedrol e antibiótico profilático. Todos os derivados sangüíneos que foram utilizados no receptor foram lavados e irradiados.

No manuseio pós-operatório, a monitorização hemodinâmica consistiu na avaliação dos seguintes 
Barbero-Marcial M, Azeka E, Camargo P R, Jatene M B, Riso A, Auler Júnior J O C, Soares J, Monteiro C, Uip D, Camargo L, Santos $\mathrm{S}$, Coelho V, Atik E, Ebaid M, Jatene A D - Características do transplante cardiaco neonatal e infantil. Rev Bras Cir Cardiovasc $1996 ; 11(2): 60-6$,

parâmetros: temperatura, freqüência cardíaca e respiratória, pressão arterial sistêmica, venosa central, de átrio esquerdo e pressão média de artéria pulmonar. As principais drogas utilizadas foram: dobutamina, isoproterenol e nitroprussiato de sódio em $100 \%$ dos casos; epinefrina e norepinefrina em $10 \%$ e nitroglicerina em $30 \%$. O tempo de uso de drogas vasoativas foi de 24 dias em crianças menores que 6 meses, e de 6 dias em crianças maiores.

As medidas profiláticas quanto aos processos infecciosos foram: isolamento reverso, imunoglobulina humana e antibioticoterapia até retirada dos drenos. O ganciclovir foi administrado quando a sorologia do receptor era negativa e a do doador positiva para o citomegalovírus; quanto a toxoplasmose, quando a sorologia do receptor foi negativa e a do doador positiva, empregou-se o esquema profilático de pirimetamina. A nistatina oral foi administrada após retirada do tubo endotraqueal para profilaxia de candidiase oral.

Do ponto de vista laboratorial, foram estudados os eletrólitos (sódio, potássio, cálcio, magnésio), a dosagem sérica da ciclosporina, o hemograma, a avaliação da função renal (niveis de uréia, creatinina e cleareance de creatinina) e a função hepática. Outros exames, tais como radiografia de tórax, eletrocardiograma, ecocardiograma e cintilografia com gálio 67 realizados em intervalo variável conforme o estado clínico dos pacientes.

A profilaxia da rejeição consistiu na utilização imediata de ciclosporina e azatioprina como drogas imunosupressoras básicas, empregando-se, paralelamente, solumedrol e linfoglobulina de coelho. A dose da ciclosporina foi controlada de acordo com - nível sérico da mesma através do método de radio-imunoensaio, mantendo-se o nivel entre 300 a $400 \mathrm{ng} / \mathrm{ml}$. A dose da azatioprina administrada variou de 1 a $3 \mathrm{mg} / \mathrm{kg} / \mathrm{dia}$, conforme o número de leucócitos em nível de sangue periférico, sendo a mesma suspensa quando era menor que 4.000 células por $\mathrm{mm}^{3}$.

O diagnóstico de rejeição aguda baseou-se no quadro clínico, eletrocardiograma, ecodopplercardiograma e cintilografia com gálio 67. A biospia endomiocárdica foi utilizada nos pacientes onde houve necessidade de estabelecer o diagnóstico diferencial com processos infecciosos miocárdicos. Para o tratamento dos quadros agudos de rejeição, foi utilizada a pulsoterapia (metilprednisolona, nas doses de $125 \mathrm{mg}$ de $12 \mathrm{em} 12$ horas durante 4 dias até $10 \mathrm{~kg}$ de peso da criança; $250 \mathrm{mg}$ de $12 \mathrm{em} 12$ horas quando o peso foi entre $10 \mathrm{~kg}$ a $20 \mathrm{~kg}$ e 500 $\mathrm{mg}$ de $12 \mathrm{em} 12$ horas quando maior que $20 \mathrm{~kg}$ ) e, dependendo da gravidade do quadro, associada a linfoglobulinas.
Após a alta hospitalar, as crianças sem adequadas condições sócio-econômicas permaneceram na Associação de Assistência à Criança Transplantada do Coração, entidade filantrópica que proporciona habitação, alimentação e acompanhamento psicológico e social, criada especialmente para possibilitar o desenvolvimento do transplante neste grupo populacional.

O acompanhamento ambulatorial foi realizado através de duas avaliações por semana nos primeiros 5 meses, quinzenalmente nos 6 meses seguintes e aumentando-se o intervalo das consultas para mensais ou trimestrais, conforme a evolução de cada criança.

\section{RESULTADOS *}

A sobrevida foi de $12(85,7 \%)$ das 14 crianças que foram submetidas ao transplante cardíaco ortotópico. Os 2 óbitos foram provocados por rejeição aguda moderada 40 dias pós-transplante e o outro por doença linfoproliferativa após 2 anos de evolução.

As principais complicações no período pós-operatório foram: hipertensão arterial sistêmica, infecção e rejeição aguda em (100\%); das infecções, as mais freqüentes foram as bacterianas $(82 \%)$, virais $(11 \%)$ e protozoários $(7 \%)$. Entre as bacterianas, assinalam-se como as mais freqüentes as pulmonares, seguidas das bacteremias primárias, tanto no pós-operatório imediato como no tardio (Quadro 1).

No seguimento evolutivo, as crianças apresentaram, do ponto de vista hematológico, série vermelha com hemoglobina entre $8,6 \mathrm{~g} \%$ a $12,9 \mathrm{~g} \%$ (média de $10,7 \mathrm{~g} \%$ ) e hematócrito de $26 \%$ a $38 \%$ (média de $32 \%$ ).

Quanto à avaliação da função renal, os níveis de uréia variaram de 25 a $91 \mathrm{mg} / \mathrm{dl}$ (média de 53

\section{QUADRO 1}

INFECÇŌES

\section{BACTERIANAS}

broncopneumonias 25

bacteremias primárias

otite média aguda

abscessos dentários

micobacteriose

infecçāo urinária

3
1
1
1

VIRAIS

6

citomegalovírus

mononucleose infecciosa

meningoencefalite

molusco infeccioso

3

1

PROTOZOÁRIOS

toxoplasmose 
Barbero-Marcial M, Azeka E, Camargo P R, Jatene M B, Riso A, Auler Júnior J O C, Soares J, Monteiro C, Uip D, Camargo L, Santos $\mathrm{S}$, Coelho V, AtikE, Ebaid M, Jatene A D - Características do transplante cardiaco neonatal e infantil. Rev Bras Cir Cardiovasc $1996 ; 11(2): 60-6$,

$\mathrm{mg} / \mathrm{dl}$ ) e a creatinina sangüínea variou de $0,6 \mathrm{mg} /$ dl a $0,9 \mathrm{mg} / \mathrm{dl}$ (média de $0,9 \mathrm{mg} / \mathrm{dl}$ ).

Os níveis séricos de ciclosporina analisados pelo método monoclonal variaram de $286 \mathrm{ng} / \mathrm{ml}$ a 555 $\mathrm{ng} / \mathrm{ml}$ (média de $381 \mathrm{ng} / \mathrm{ml}$ ).

A função hepática revelou níveis de aspartato aminotransferase (TGO) entre $5 \mathrm{U} / \mathrm{l}$ e $29 \mathrm{U} / \mathrm{I}$ (média de $17,9 \mathrm{U} / \mathrm{I}$ ) e de alanina aminotreansferase (TGP) entre 6 U/I e 29 U/I (média de 14,3 U/I). A avaliação do eletrocardiograma seriado pós-operatório mostrou morfologia de distúrbio de condução do ramo direito em $100 \%$ dos casos. O índice cardiotorácico avaliado pela radiografia de tórax mostrou valores normais variando entre 0,5 e 0,66 (média de 0,58 ). A função ventricular avaliada pelo ecocardiograma mostrou fração de encurtamento entre $31 \%$ e $43 \%$ (média de $35,5 \%$ ).

No diagnóstico de rejeição aguda, os elementos clínicos presentes foram: alteraçōes de humor (60\%), anorexia $(42 \%)$, febre $(34 \%)$, insuficiência cardíaca congestiva ( $23 \%)$, alterações do trato intestinal ( $8 \%)$, arritmias $(2,6 \%)$. A queda do somatório do complexo QRS no eletrocardiograma esteve presente em $90 \%$ dos casos. Esta queda variou de $7 \%$ a $48 \%$ (média de $24,8 \%$ ). No ecodopplercardiograma observou-se no momento do diagnóstico da rejeição: derrame pericárdico em $21 \%$, aparecimento de insuficiência de valva atrioventricular em $31,5 \%$ e aumento da medida de septo e parade posterior do ventrículo esquerdo em $21 \%$ dos casos.

Durante a evolução clínica pós-operatória, foram realizados 90 estudos com a cintilografia com gálio 67 nas crianças transplantadas. Cinco estudos apresentaram resultado positivo. Nestes pacientes a biopsia confirmou o quadro de rejeição aguda. Nos pacientes que tiveram estudos de gálio 67 negativos houve correlação clínica com ausência de sinais sugestivos de rejeição.

Os quadros de rejeição aguda foram controlados com pulsoterapia, linfoglobulina de cavalo e de coelho em $80 \%$ dos casos. Em 1 caso foi necessário o emprego de metrotrexate para que a criança melhorasse da complicação e, no outro, a criança faleceu no segundo dia de pulsoterapia, por rejeição aguda moderada observada no estudo histopatológico.

Globalmente, houve em média 3,5 episódios de rejeição e 3,3 episódios de infecção por paciente. O tempo de seguimento foi em média de 16 meses (1 a 42 meses).

\section{COMENTÁRIOS}

As características que, na nossa experiência, foram consideradas relevantes no transplante car- diaco infantil foram: conhecimento das peculiaridades anatômicas nas diversas cardiopatias congênitas (hipoplasia de coração esquerdo, atresia pulmonar com septo íntegro, situs inversus com drenagem anômala e atresia pulmonar com anomalias de artérias pulmonares), manuseio pré e pós-operatório dos potenciais receptores; necessidade de compatibilidade de peso entre receptor e doador; diagnóstico de morte encefálica de acordo com a faixa etária; presença de janela imunológica no recémnato; imunomodulação da resposta neonatal aloantigênica (Gráfico 1); esquema de imunizações com vírus mortos; farmacocinética da ciclosporina em crianças; métodos não invasivos para o diagnóstico de rejeição aguda.

Uma característica desta faixa etária é a do manuseio pré e pós-operatório, que assume importância fundamental, pois a mortalidade dos receptores é de aproximadamente $60 \%$, no nosso meio, enquanto se aguarda o transplante. Os fatores de risco descritos incluem instabilidade hemodinâmica, acesso venoso central, suporte ventilatório, hipertensão pulmonar (6). Sabe-se que, de acordo com a cardiopatia, a criança irá se beneficiar com determinado tipo de terapêutica pré-operatória, enquanto se aguarda o transplante.

Os critérios de inclusão do receptor são importantes, pois deles dependerão o sucesso ou não do transplante: idade gestacional maior que 36 semanas e peso de nascimento maior que 2.200 gramas, estabilidade metabólica e hemodinâmica, ausência de quadros sépticos, neurológicos, renais e anormalidades cromossômicas, bem como ausência de distúrbios psiquiátricos nos responsáveis pela criança. Quanto à hipertensão pulmonar, preconiza-se índice de resistência vascular pulmonar menor que 6 unidades Woods e gradiente transpulmonar (pressão média de artéria pulmonar menos pressão de capilar pulmonar) menor que $15 \mathrm{mmHg}$ em repouso

GRÁFICO 1

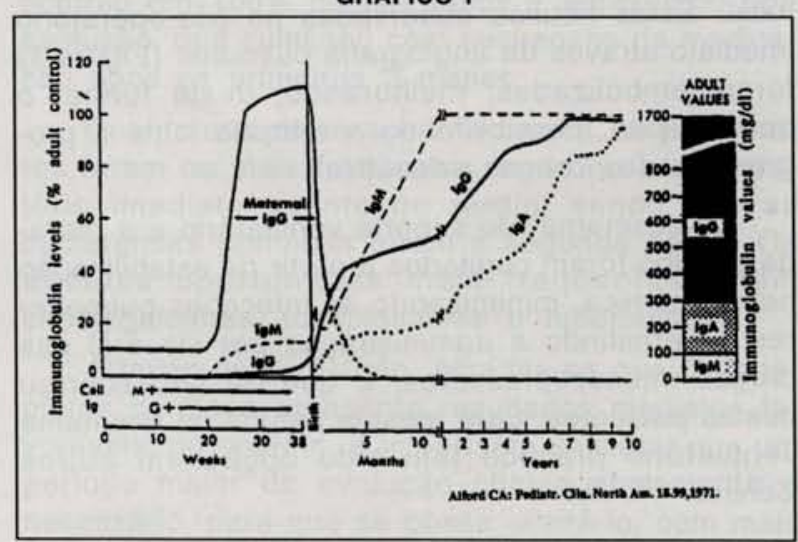

Concentração de imunoglobulinas no feto, recém-nascido, lactente $e$ criança, segundo Alford CA, 1971. 
Barbero-Marcial M, Azeka E, Camargo P R, Jatene M B, Riso A, Auler Júnior J O C, Soares J, Monteiro C, Uip D, Camargo L, Santos $\mathrm{S}$, Coelho V, Atik E, Ebaid M, Jatene A D - Características do transplante cardiaco neonatal e infantil. Rev Bras Cir Cardiovasc $1996 ; 11(2): 60-6$

ou após emprego de vasodilatadores (nitroprussiato de sódio, oxigênio ou óxido nítrico) pois índices acima destes valores implicam em maior mortalidade per-peratória $(8,9)$. Todos os pacientes apresentados neste trabalho tiveram índice de resistência vascular pulmonar menor que 6 unidades Wood, encontrando-se a média dentro dos limites da normalidade.

No manuseio pós-operatório, preconiza-se monitorização hemodinâmica através da freqüência cardíaca e respiratória, da pressão arterial sistêmica, venosa central, de átrio esquerdo e da média de artéria pulmonar. As pressões em artéria pulmonar e atrial direita são úteis quando há evidências de falência ventricular direita por hipertensão pulmonar. Nestes casos, as drogas de escolha são prostaglandina $E 1$; vasodilatadores sistêmicos não seletivos, como nitroprussiato de sódio, e/ou inalatório pulmonar seletivo, como óxido nítrico. Em casos extremos de falência ventricular, está indicada a oxigenação extracorpórea (ECMO), porém esta técnica requer anticoagulação, o que implica em aumento do risco de sangramento (10). A disfunção ventricular direita por hipertensão pulmonar ocorreu em $20 \%$ das nossas crianças operadas, com melhora após vasodilatadores não seletivos, como o nitroprussiato de sódio.

As drogas vasoativas de escolha foram cronotrópicas, como isoproterenol em baixas doses, uma vez que o coração é desnervado; inotrópicas, como dobutamina, dopamina, amnrinone, sendo que a epinefrina e a norepinefrina foram indicadas somente em casos de acentuado baixo débito. O emprego de inotrópicos foi, em geral, por um período curto de tempo, principalmente em crianças maiores que 6 meses. A epinefrina e a noradrenalina foram utilizadas apenas em 1 caso, pelo baixo débito, em decorrência de fístulas arteriovenosas pulmonares após cirurgia de Blalock-Taussig em criança portadora de atresia pulmonar com sinusóides, submetida a este procedimento paliativo no período neonatal. Estas fístulas observadas no pós-operatório imediato através da angiografia pulmonar (Figura 1) foram embolizadas, melhorando, desta forma, o baixo débito, possibilitando a retirada lenta e progressiva das drogas vasoativas.

O "desmame" do suporte ventilatório e a retirada do tubo foram cogitados a partir da estabilização hemodinâmica, minimizando as infecções pulmonares e permitindo a administração por via oral das drogas imunosupressoras, o que de fato ocorreu nestes pacientes. Esta mesma atitude de desmame ventilatório precoce tem sido opção em outros Centros (10-12).

As medidas profiláticas, em relação aos processos infecciosos, constituem outra característica im-

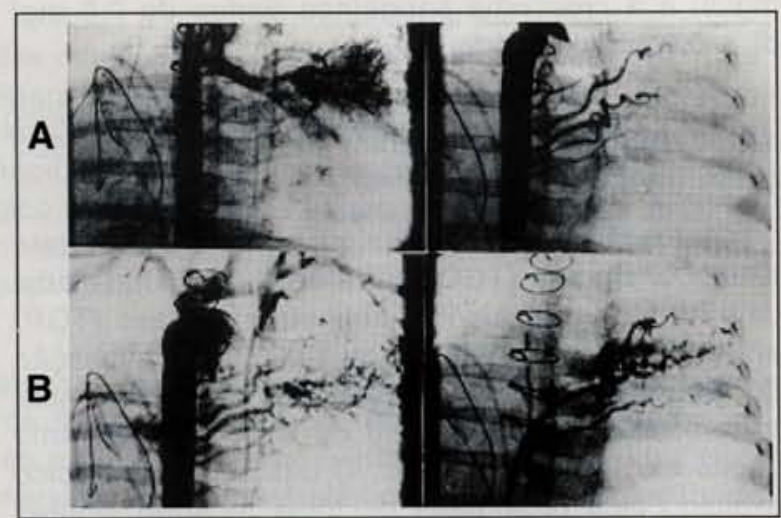

Fig 1 - A : Fistulas arteriopulmonares; B: Embolização com gelfoan.

portante a salientar, que devem ser tomadas: isolamento reverso, \&munoglobulina humana e cefazoline até retirada dos drenos, porém não foram suficientes para evitar uma incidência elevada de eventos infecciosos (3,3 eventos/paciente) e que, no entanto, puderam ser controlados com a medicação especifica.

O ganciclovir profilático foi utilizado apenas quando o receptor apresentava sorologia negativa para o citomegalovírus e o doador, conversão sorológica; o mesmo acontecendo com a toxoplasmose, quando o receptor apresentou sorologia negativa e o doador, títulos de conversão sorológica; o esquema profilático foi com pirimetamina.

Nesta casuística, o número de pacientes que necessitaram de profilaxia para CMV e toxoplasmose foram $20 \%$ e $30 \%$, respectivamente, e os que apresentaram soroconversão foram $30 \%$ e $40 \%$. A evolução foi satisfatória em ambos os casos. É importante salientar que, tanto o citomegalovirus como a toxoplasmose acarretam infecções graves se não diagnosticadas e tratadas precocemente, podendo a criança evoluir para êxito letal.

Em relação aos protocolos de imunosupressão, existem diversos esquemas empregados, desde monoterapia até triplos (ciclosporina, azatioprina e corticóide). A farmacocinética da ciclosporina apresenta características peculiares em crianças. A ciclosporina constitui-se na droga clássica principal, atuando na inibição da proliferação de linfócitos $T$, sendo que o nível sérico pode ser controlado através de vários métodos, como radioimunoensaio ou através da fluorescência indireta. $O$ método optado foi o radioimunoensaio, por dosar preferencialmente a ciclosporina sérica e não os metabólicos. Na nossa experiência, tivemos problemas com a administração oral da ciclosporina em 2 casos: 1 paciente necessitou de altas doses da medicação e o outro necessitou de administração da ciclosporina endovenosa por via oral para atingir os níveis séricos preconizados. 
Barbero-Marcial M, Azeka E, Camargo P R, Jatene M B, Riso A, Auler Júnior J O C, Soares J, Monteiro C, Uip D, Camargo L, Santos $\mathrm{S}$, Coelho V, Atik E, Ebaid M, Jatene A D - Características do transplante cardiaco neonatal e infantil. Rev Bras Cir Cardiovasc $1996 ; 11(2): 60-6$,

A azatioprina, a segunda droga imunosupressora que atua bloqueando a proliferação de linfócitos, é convertida a mercaptopurina, que inibe a síntese e a utilização de precursores de RNA e DNA, podendo ser administrada por via oral ou endovenosa. O seu principal efeito colateral é hematológico, onde a leucopenia menor que 4.000 leucócitos contra-indica sua continuidade, o que, de fato, foi uma complicação freqüente na nossa experiência, obrigando sua suspensão temporária.

A profilaxia da rejeição iniciou-se no pós-operatório imediato com as duas drogas citadas acima; utilizou-se, paralelamente, metilprednisolona e linfoglobulina.

Há grupos que utilizam a corticoterapia como parte do esquema de imunosupressão de base por tempo indeterminado; no entanto, há controvérsias, principalmente no que diz respeito ao aumento do risco de processos infecciosos e em distúrbios de crescimento por fechamento precoce dos núcleos de ossificação. Nestas crianças, a imunosupressão de base consistiu de esquema duplo: ciclosporina e azatioprina.

As linfoglobulinas foram utilizadas na profilaxia logo no pós-operatório imediato, quando não houve presença de efeitos colaterais, como plaquetopenia e coagulopatia (8). Estudo comparativo de 1993, em Loma Lina ${ }^{(9)}$, realizado entre grupos de crianças que utilizaram a linfoglobulina de coelho como profilaxia nos primeiros 5 dias e grupo controle, mostrou uma diminuição no número de rejeições, aparecimento tardio do primeiro episódio de rejeição aguda no grupo que recebeu a profilaxia quando comparado com o controle.

O diagnóstico de rejeição aguda através de métodos não invasivos é outra característica nas crianças transplantadas. Na nossa casuística, a rejeiçāo aguda ocorreu principalmente nos primeiros 4 meses de transplante, sendo seu diagnóstico precoce e tratamento essenciais para a boa evolução.

Os principais sinais clínicos observados nos pacientes estudados foram desde alteraçōes do ritmo cardiaco de base (aumento da freqüência cardiaca, arritmias, bradicardia, presença de terceira bulha), sinais de insuficiência cardíaca e sinais inespecíficos (irritablidade, anorexia, alteração de humor). No eletrocardiograma notou-se queda do somatório das voltagens do QRS maior que $20 \%$. No ecodopplercardiograma foram avaliados função ventricular, diâmetro das cavidades, medida da espessura do septo e parede posterior, presença de insuficiência das valvas atrioventriculares e derrame pericárdico.

A cintilografia com gálio 67 na rejeição aguda, publicada em nosso meio por MENEGUETTI et al. (13) foi realizada periodicamente no pós-operatório e auxiliou em muito no diagnóstico de rejeição. A biopsia endomiocárdica, apesar de fornecer o diag- nóstico de certeza, apresenta riscos; daí ter sido indicada apenas quando houve positividade da cintilografia com gálio, nos casos de diagnóstico diferencial com processos infecciosos miocárdicos, como citomegalovírus e toxoplasmose.

O tratamento da rejeição aguda dependeu do quadro hemodinâmico da criança. A pulsoterapia isolada foi utilizada em $100 \%$ dos casos e sua associação com linfoglobulinas foi em $28 \%$. O controle da rejeição foi possível em $93 \%$ dos casos, sendo que houve 1 óbito por rejeição aguda moderada no primeiro caso operado, apesar do tratamento com pulsoterapia ter sido iniciado 2 dias antes.

A linfoglobulina de escolha, quando necessário, foi a de cavalo (ATGAM), sendo o aumento da dose controlado através do número de lifócitos $T$ a nível de sangue periférico, pela citometria de fluxo. $O$ emprego de linfoglobulina de coelho ocorreu quando não houve resposta na utilização do ATGAM, observada através do quadro clínico, parâmetros eletrocardiográficos e ecocardiográficos, bem como ausência de queda adequada do número de linfócitos em nível de sangue periférico.

A criança transplantada necessita ser acompanhada ambulatorialmente após a alta hospitalar, no sentido de prevenção e tratamento de potenciais complicaçōes.

As principais complicações descritas ao longo da evolução na literatura são a rejeição aguda, processos infecciosos, hipertensäo arterial sistêmica, coronariopatia, insuficiência renal e doença linfoproliferativa. Nesta casuística, as principais complicações foram, além da rejeição aguda, processos infecciosos e hipertensão arterial sistêmica, sendo que ocorreu 1 óbito por doença linfoproliferativa 2 anos após transplante.

A hipertensão arterial sistêmica foi comum no pós-operatório imediato, sendo controlada através de vasodilatadores, como nitroprussiato de sódio, apresoline, nifedipina e captopril. Esta complicação ocorreu em $100 \%$ destes casos e apresentou boa evolução, que culminou com suspensão da medicação após os primeiros 3 meses.

Quanto aos processos infecciosos, os pulmonares foram os mais freqüentes, tanto no pós-operatório imediato quanto no tardio, sendo que as bacteremias primárias foram a segunda causa. Os agentes oportunistas mais freqüentes foram citomegalovírus, toxoplasmose e tuberculose.

Através deste estudo, acredita-se que o transplante cardíaco apresenta resultados mediatos favoráveis; no entanto, é importante salientar que um período maior de evolução clínica obviamente é necessário, para que se possa aceitá-lo, com mais segurança e melhores perspectivas, como mais uma opção terapêutica. 
Barbero-Marcial M, Azeka E, Camargo PR, Jatene M B, Riso A, Auler Júnior J O C, Soares J, Monteiro C, Uip D, Camargo L, Santos S, Coelho V, Atik E, Ebaid M, Jatene A D - Características do transplante cardíaco neonatal e infantil. Rev Bras Cir Cardiovasc $1996 ; 11(2): 60-6$,

Barbero-Marcial M, Azeka E, Camargo P R, Jatene M B, Riso A, Auler Júnior J O C, Soares J, Monteiro C, Uip D, Camargo L, Santos S, Coelho V, Atik E, Ebaid M, Jatene A D - Characteristics of heart transplantation in neonates and infants. Rev Bras Cir Cardiovasc 1996; 11 (2): 60-6.

ABSTRACT: Objective: Relate the characteristics of the heart transplantation in children with complex congenital heart diseases and severe cardiomyopathies. The present article was written to show the three year experience of this procedure at the Instituto do Coração HC-FMUSP.

Methods: The methodology used was based on surgical procedure in congenital heart disease, heart transplant indication criteria, inclusion criteria for donors, postoperative management, immunosupression and prophylaxis as well as treatment for potential complications.

Results: From November 1992 to June 1996, fourteen children, aged 12 days old to six years of age (mean: 2.2 years), underwent transplantation. Fifty-seven percent of recipients were male; weight ranged from 3.5 to $17.8 \mathrm{~kg}$ (mean: $10.3 \mathrm{~kg}$ ). The mean age of donors was 4.4 years (a range of three weeks to ten years), $80 \%$ male, weight ranging from 3.8 to $20 \mathrm{~kg}$ (median $14.3 \mathrm{~kg}$ ). The survival rate was $85.7 \%$ (two deaths in 14 patients). The follow-up was between one month to three years (average 16 months). The most important complications were systemic hypertension, acute rejection and infection. The number of rejections and infections per patient were 3.5 and 3.3 episodes respectively.

Conclusions: In this experience heart transplantation has been giving a chance for children with complex congenital heart diseases and cardiomyopathies, with a survival rate of $85.7 \%$.

DESCRIPTORS: Heart transplantation, neonatal. Heart transplantation, pediatric.

\section{REFERÊNCIAS BIBLIOGRÁFICAS}

1 Barnard C N - A Human cardiac transplant: an interim report of a successful operation performed at Gröote Schuur Hospital, Cape Town. S Afr Med J 1967; 41: 1271-4.

2 Kantrowitz A, Haller J D, Joos $\mathrm{H}$ et al. - Transplantation of the heart in an infant and an adult. Am J Cardiol 1968; 22: 782-90

3 Kahan B D - Immunosuppressive therapy with cyclosporine for cardiac transplantation. Circulation 1987; 75: 40-56.

4 BAILEY L L, NEHLSEN-CANNARELLA S L, CONCEPCION W et al. - Baboon-to-human cardiac xenotransplantation in a neonate. JAMA 1985; 254: 3321-9.

5 Bailey L L, Nehlsen-Cannarella S L, Doroshow R W et al. - Cardiac allotransplantation in newborns as therapy for hypoplastic left heart syndrome. NEJM 1986; 315: 949-51.

6 Razzouk A J \& Bailey L L - Infant heart transplantation. In: Emmanouilides G C, Riemenschneider T A, Allen H D, Gutgesell H P, eds. Moss and Adams Heart disease in infants, children and adolescents including the fetus and young adult. 5th ed. Baltimore: Williams \& Wilkins, 1995; 510-9.
7 Barbero-Marcial M, Azeka E, Camargo P R et al. Transplante cardiaco neonatal $\theta$ infantil. Arq Bras Cardiol 1996; (No prelo).

8 International Heart and Lung Transplantation SocietyPediatric heart transplantation. Heart Lung Transplant 1993; 12: S153-S378.

9 Loma Linda Pediatric Heart Transplantation Protocol. Loma Linda: Loma Linda University, 1993; 1-119.

10 Castañeda A, Jonas R A, Mayer J E et al. - Cardiac surgery of the neonate and infant. Philadelphia: WB Saunders Company, 1994; 467-78.

11 Fricker $\mathrm{F} \mathrm{J}$ \& Armitage $\mathrm{J} \mathrm{M}$ - Heart and heart-lung transplantation in children and adolescents. In: Emmanouilides G C, Riemenschneider T A, Allen H $D$, Gutgesell H P, eds. Moss and Adams heart disease in infants, children and adolescents including the fetus and young adult. 5 th ed. Baltimore: Willians \& Wilkins, 1995; 495-509.

12 Kirklin J W \& Barrat-Boyes B - Cardiac surgery. 2nd ed. New York: Churchill Livingstone Inc, 1993; 1655-81.

13 Meneguetti J C, Camargo E E, Soares Jr. J et al. Gallium-67 imaging in human heart transplantation: correlation with endomyocardial biopsy. $J$ Heart Transplant 1987; 6: 171-6. 